\title{
Flora do Espírito Santo: Bertolonia (Melastomataceae)
}

\author{
Flora of Espírito Santo: Bertolonia (Melastomataceae)
}

\author{
Lucas F. Bacci ${ }^{1,5}$, André M. Amorim ${ }^{2,3}$ \& Renato Goldenberg ${ }^{4}$
}

\begin{abstract}
Resumo
Este estudo trata das espécies de Bertolonia (Melastomataceae) encontradas no estado do Espírito Santo, Brasil. O trabalho é baseado em análise morfológica de coleções depositadas em herbários, bibliografia específica e coletas de campo. Um total de nove espécies foram registradas, a maioria endêmica no estado, além de uma nova espécie (B. michelangeliana). São apresentadas uma chave de identificação atualizada, descrições, status de conservação e comentários sobre a distribuição das espécies.
\end{abstract}

Palavras-chave: Bertolonieae, endemismo, Floresta Atlântica, taxonomia.

\begin{abstract}
This study focuses on the species of Bertolonia (Melastomataceae) found in the state of Espírito Santo, Brazil. It is based on the analysis of herbarium collections, specific bibliography and collections in the field. A total of nine species were recorded for the state, most of them endemic to the state, with one new species (B. michelangeliana). An updated identification key, descriptions and comments about species distributions are also provided.
\end{abstract}

Key words: Bertolonieae, endemism, Atlantic Forest, taxonomy.

\section{Introdução}

Melastomataceae Juss. é um grupo monofilético caracterizado pelas folhas com nervuras geralmente acródromas, flores radiais, bissexuais e diplostêmones, e estames com conectivo robusto, geralmente alongado e apendiculado (Clausing \& Renner 2001). É a sétima maior família de angiospermas no estado do Espírito Santo, com 197 espécies distribuídas em 26 gêneros (BFG 2015; Dutra et al. 2015). A família começou a ser estudada extensivamente no estado apenas nas últimas duas décadas, com tratamentos locais ou estaduais (Goldenberg \& Reginato 2006; Meirelles \& Goldenberg 2012; Bacci et al. 2016c) e várias espécies novas foram descritas nos últimos dez anos (Goldenberg \& Tavares 2007; Tavares et al. 2008; Goldenberg \& Reginato 2009; Goldenberg \& Kollmann 2010, 2016; Camargo \& Goldenberg 2011; Caddah \& Goldenberg 2012; Meirelles et al. 2012; Bacci \& Goldenberg 2015; Iglesias et al. 2016; Meyer et al. 2016).
Bertolonia Raddi é um gênero endêmico na Floresta Atlântica (Bacci et al. 2016a), e suas espécies habitam geralmente áreas sombreadas e úmidas, em locais com relevo acidentado (Baumgratz 1990). As características marcantes que circunscrevem o gênero são seu hábito herbáceo, anteras geralmente uniporosas, dorsalmente apendiculadas e os frutos secos, do tipo cápsulas obtriquetras ("bertolonídio", segundo Baumgratz 1983-1985), com sementes que são dispersas pela chuva (Pizo \& Morellato 2002). O gênero tem 25 táxons válidos, dos quais oito foram registrados no Espírito Santo (BFG 2015; Bacci et al. 2016a). Sete espécies novas de Bertolonia foram descritas nos últimos seis anos (Baumgratz et al. 2011; Bacci et al. 2016a, 2016b; Silva-Gonçalves et al. 2016), três delas endêmicas no estado (Bertolonia duasbocaensis Bacci \& R.Goldenb., B. macrocalyx Bacci \& R.Goldenb. e B. ruschiana Bacci \& R.Goldenb.). Análises recentes de espécimes de herbário indicam nove espécies de Bertolonia no

\footnotetext{
${ }^{1}$ Universidade Estadual de Campinas, Depto. Botânica, Prog. Pós-graduação em Biologia Vegetal, R. Monteiro Lobato 255, 13083-970, Campinas, SP, Brasil.

${ }^{2}$ Universidade Estadual de Santa Cruz, Depto. Ciências Biológicas, Salobrinho, 45622-900, Ilhéus, BA, Brasil.

${ }^{3}$ Centro de Pesquisas do Cacau Herbário CEPEC, Av. Juca Leão 463, C.P. 07, 45600-970, Itabuna, BA, Brazil.

${ }^{4}$ Universidade Federal do Paraná, Centro Politécnico, Depto. Botânica, Av. Cel. Francisco H. dos Santos s/n, C.P. 19031, 81531-970, Curitiba, PR, Brasil.

${ }^{5}$ Autor para correspondência: lucasfbacci@gmail.com
} 
Espírito Santo, uma delas ainda não descrita. Aqui nós apresentamos o tratamento taxonômico para o gênero no estado do Espírito Santo com chave de identificação atualizada, descrições e comentários sobre a distribuição das espécies.

\section{Material e Métodos}

Os autores vêm coletando Bertolonia no Espírito Santo desde 2008, seguindo os procedimentos usuais para coleta e herborização de material botânico (Mori et al. 1989). Este estudo foi baseado em literatura específica (Baumgratz 1990; Baumgratz et al. 2011; Bacci et al. 2016a) e na análise de espécimes depositados em CEPEC, CVRD, ESA, HUFU, K, MBM, MBML, NY, RB, SPF, UEC, UPCB, US, VIES (acrônimos segundo Thiers, continuamente atualizado). Para informações sobre a classificação da vegetação que recobre o Espírito Santo, ver Garbin et al. (2017).

Tendo em vista que três das espécies aqui tratadas (B. duasbocaensis, B. macrocalyx e $B$. ruschiana) foram recentemente descritas, e exatamente pelos mesmos autores deste trabalho (Bacci et al. 2016a), não houve adição de novas coletas à amostragem já utilizada anteriormente e, desta forma, as descrições aqui apresentadas para estas três espécies são muito semelhantes (embora menos detalhadas) àquelas apresentadas no artigo de 2016. A chave de identificação para as espécies de Bertolonia no Espírito Santo apresentada aqui é uma atualização da versão publicada por Bacci et al. (2016a), com a inclusão de duas espécies ( $B$. mosenii e B. michelangeliana).

\section{Resultados e Discussão}

Taxonomia

Bertolonia Raddi Mem. Mat. Fis. Soc. Ital. Sci. Modena, Pt. Mem. Fis. 18: 384.

Ervas terrestres, rupícolas ou hemiepífitas, raro reptantes; caule cilíndrico a quadrangular e levemente costado, ramos velhos plagiotrópicos, áfilos, jovens sustentando as folhas, eretos, revestidos por glândulas curto-pedunculadas (menores que $0,1 \mathrm{~mm}$ compr.), às vezes também com tricomas simples nos ramos, folhas, inflorescência e hipanto. Folhas opostas, ocasionalmente subopostas ou alternas; pecíolo glanduloso, glandulosopiloso ou glanduloso-viloso, hirsuto ou viloso; lâmina plana ou bulada/foveolada, lanceolada a largamente elíptica, ovada, raro cordiforme, três a nove nervuras, mais um par marginal inconspícuo. Tirsóides escorpióides. Flores 5-meras, hipanto curto-cilíndrico a largamente campanulado, sépalas fusionadas ou não com os dentes externos. Pétalas brancas a rosas, ápice agudo, apiculado, com ou sem um tricoma simples no ápice, ou não apiculado, margem inteira ou ciliada no ápice, glabra ou com ápice da face adaxial esparsamente revestido por glândulas curto-pedunculadas (menores que $0,1 \mathrm{~mm}$ compr.). Estames 10, cremes ou amarelos; anteras oblongo-subulados ou longo-subulados deiscentes por um poro introrso ou extrorso; pedoconectivo prolongado abaixo das tecas, inapendiculado, giboso ou dorsalmente calcarado. Ovário glabro, estilete reto ou curvado no ápice. Frutos capsulares, tipo bertolonídeo (seguindo Baumgratz 19831985); sementes triangulares, tuberculadas no ápice.

\section{Chave de identificação das espécies de Bertolonia no estado do Espírito Santo, Brasil (traduzida e adaptada de Bacci et al. 2016a)}

1. Folhas alternas; anteras deiscentes por um poro extrorso 6. Bertolonia michelangeliana sp. nov.

1'. Folhas opostas ou ocasionalmente sub-opostas; anteras deiscentes por um poro introrso

2. Lâminas foliares com superfície bulada/foveolada

3. Pecíolos vilosos; sépalas com margem inteira; pétalas 5,5-7 $\mathrm{mm}$ compr.

3'. Pecíolos hirsutos; sépalas com margem fimbriada; pétalas 7,5-8,5 mm compr.

2'. Lâminas foliares com superfície plana

4. Lâminas foliares com superfície abaxial e/ou adaxial permanentemente cobertas com glândulas curto-pedunculadas e tricomas simples, longos....

5. Pecíolos com ápice hirsuto; flores $17,5-22 \mathrm{~mm}$ compr.; sépalas com margens curtofimbriadas; pétalas com margens inteiras; pedoconectivo dorsalmente calcarado 
5'. Pecíolos glanduloso-pilosos ou glanduloso-vilosos em toda sua extensão; flores ca. $12 \mathrm{~mm}$ compr.; sépalas com margens inteiras; pétalas com margens ciliadas no ápice; conectivo inapendiculado

5. Bertolonia maculata

4'. Lâminas foliares com superfícies abaxial e adaxial cobertas apenas com glândulas curtopedunculadas.

6. Lâminas foliares $5-8,5 \times 4-6,5 \mathrm{~cm}$, ovais a largamente elípticas, base aguda a obtusa.

7. Bertolonia mosenii

6'. Lâminas foliares 7,8-18,5 × 4,5-10 cm, lanceoladas a elípticas, base arredondada a levemente cordada.

7. Hipanto coberto somente por glândulas curto-pedunculadas; pétalas 6-6,5 $\mathrm{mm}$ compr., largamente obovadas 8. Bertolonia ruschiana

7'. Hipanto coberto por glândulas sésseis ou curto-pedunculadas e por tricomas simples; pétalas 7-12 mm compr., irregularmente elípticas .8

8. Flores 13,3-14,7 mm compr.; cálice com dentes externos ca. $1 \mathrm{~mm}$ compr., triangulares, revestidos somente por glândulas curto-pedunculadas; pétalas apiculadas (ca. 0,5 mm compr.), o apículo sem tricoma no ápice. 1. Bertolonia duasbocaensis

8'. Flores 9,5-11,2 mm compr.; cálice com dentes externos ca. 2 mm compr., ovados revestidos por glândulas curto-pedunculadas e também por tricomas simples, esparsos; pétalas apiculadas (ca. $1 \mathrm{~mm}$ compr.), o apículo com um tricoma simples no ápice.......

4. Bertolonia macrocalyx

1. Bertolonia duasbocaensis Bacci \& R.Goldenb., PeerJ 4: e2822, p. 3. 2016. Fig. 1a,b

Ervas $10-35 \mathrm{~cm}$ alt. Ramos, folhas e inflorescências revestidos por glândulas curtopedunculadas (menores que 0,1 $\mathrm{mm}$ compr.), ramos jovens esparsamente revestidos por tricomas simples. Folhas opostas, ocasionalmente subopostas; pecíolos 3-9,5 cm compr., com o mesmo indumento dos ramos; lâmina 7,8-11,7 × 4,5-9 $\mathrm{cm}$, plana, elíptica, base arredondada a levemente cordada, ápice arredondado a levemente agudo, margem inteira a levemente crenulada, ciliada, face adaxial verde-escura, com uma faixa branca ao longo da nervura principal, face abaxial verde-clara a lilás, três a cinco nervuras principais. Tirsóides $4,5-10,7$ cm compr. Flores 13,3-14,7 mm compr. Hipanto 2,5-2,7 $\times$ ca. $2 \mathrm{~mm}$, largamente campanulado, revestido por tricomas semelhantes ao das folhas, além de tricomas simples, longos, esparsos. Sépalas truncadas, dentes externos ca. $1 \mathrm{~mm}$ compr., triangulares, margem inteira, ambos revestidos somente por glândulas curto-pedunculadas. Pétalas brancas com ápice rósea-claro, 10,8-12 ×4,5-5 mm, irregularmente elípticas, base levemente atenuada, ápice agudo e apiculado (ca. 0,5 mm compr.), apículo sem tricoma no ápice, margem inteira, ambas superfícies papilosas, ápice da face adaxial com glândulas curto-pedunculadas esparsas. Estames 6-7 mm compr.; filetes 3,5-4 mm compr.; anteras amarelas, 2-3 $\mathrm{mm}$ compr., oblongo-subuladas, levemente onduladas, poro introrso; pedoconectivo ca. $1 \mathrm{~mm}$ compr., dorsalmente calcarado. Estilete ca. $5 \mathrm{~mm}$ compr., curvado no ápice, glabro. Cápsula 4-5 $\times 4,5-6 \mathrm{~mm}$; sementes $0,4-0,5 \mathrm{~mm}$ compr.

Material examinado: Cariacica, 10.I.2007, fl. e fr., A.P. Fontana 2584 (MBML, RB, UPCB); 10.I.2007, fl., L.C. Kollmann 9457 (MBML); 15.II.2008, fl., R.C. Forzza 5035 (MBM, MBML, RB, UPCB); 20.VII.2008, fr., A.M. Amorim 7571 (MBM, RB, UPCB); 22.VII.2008, fr., $R$. Goldenberg 1210 (MBML, RB, UPCB); 18.I.2009, fl. e fr., $R$. Goldenberg 1249 (MBML, RB, UPCB). Viana, 19.I.2009, fl., R. Goldenberg 1257 (MBML, RB, UPCB).

Bertolonia duasbocaensis é endêmica no estado do Espírito Santo (Bacci et al. 2016a). A espécie caracteriza-se pelas folhas ovadas a elípticas com a base arredondada a levemente cordada recobertas somente por glândulas curto-pedunculados, pelas flores com hipanto campanulado, com sépalas truncadas e pelas pétalas apiculadas com o ápice revestido por tricomas curtopedunculados na face adaxial (Bacci et al. 2016a). Bertolonia duasbocaensis foi coletada poucas vezes, e somente em dois municípios vizinhos [Cariacica e Viana (Fig. 2c)]. Seus espécimes habitam encostas sombreadas e úmidas entre $500-600 \mathrm{~m}$ alt. e foram coletados com flores em janeiro e fevereiro e com frutos em janeiro, fevereiro e julho (Bacci et al. 2016a). De acordo com os parâmetros da IUCN (IUCN Standards and Petitions Subcommittee 2014), B. duasbocaensis foi classificada por Bacci et al. (2016a) como "criticamente ameaçada" (CR). 

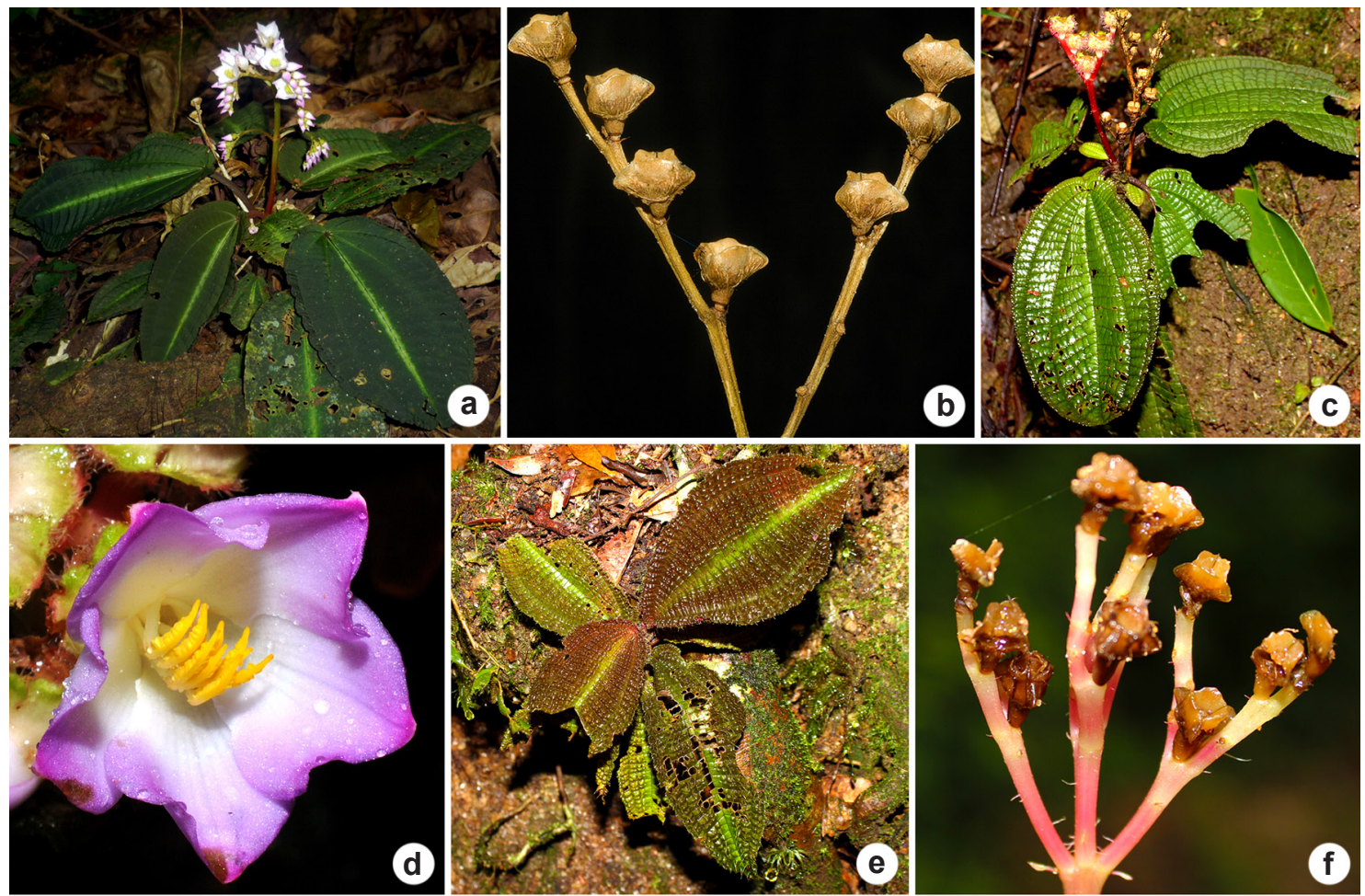

(b)
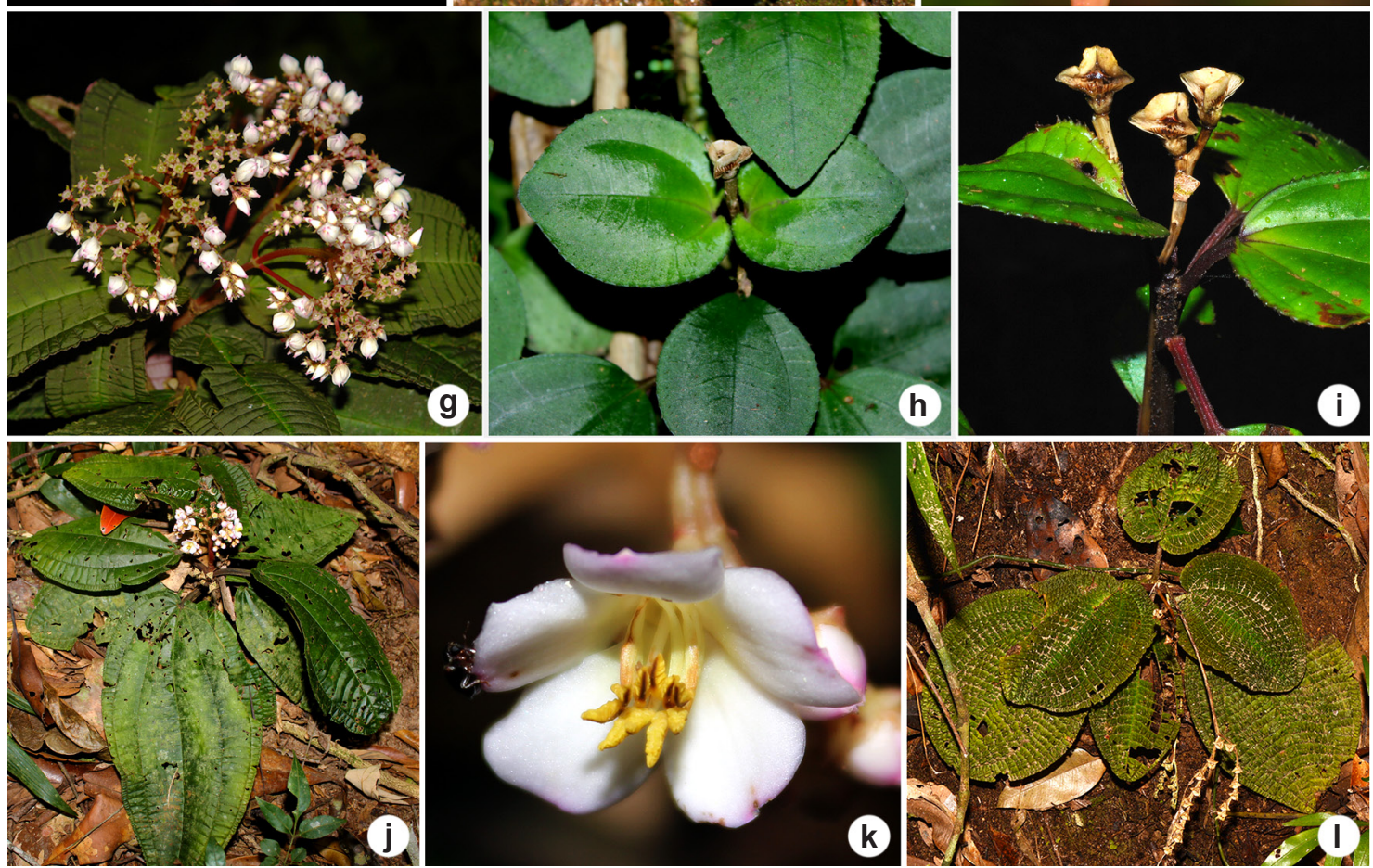

Figura 1 - Espécies de Bertolonia do Espírito Santo - a. hábito de B. duasbocaensis; b. frutos de B. duasbocaensis; c. hábito de B. formosa; d. flor de B. formosa; e. hábito de B. foveolata; f. frutos de B. foveolata; g. inflorescência de B. macrocalyx (photo: C.N. Fraga); h. hábito de B. mosenii; i. frutos velhos de B. mosenii; j. hábito de B. ruschiana; k. flor de $B$. ruschiana; 1 . hábito de $B$. wurdackiana.

Figure 1 - Species of Bertolonia from Espírito Santo - a. habit of B. duasbocaensis; b. fruits of B. duasbocaensis; c. habit of B. formosa; d. flower of $B$. formosa; e. habit of $B$. foveolata; $f$ f fruits of $B$. foveolata; $\mathrm{g}$. inflorescence of $B$. macrocalyx (photo: C.N. Fraga); h. habit of B. mosenii; i. old fruits of $B$. mosenii; j. habit of B. ruschiana. k. flower of B. ruschiana; 1 . habit of $B$. wurdackiana. 
2. Bertolonia formosa Brade, Arq. Jard. Rio Jan. 14: 224. 1956.

Fig. 1c,d

Ervas 10-40 cm alt. Ramos, folhas, inflorescências e hipanto revestidos por glândulas curto-pedunculadas (menores que $0,1 \mathrm{~mm}$ compr.) e tricomas simples, longos e esparsos. Folhas opostas, ocasionalmente sub-opostas; pecíolos 2,3-22 cm compr., com tricomas semelhantes aos dos ramos, hirsutos no ápice; lâmina 5,6-23 × 4-14 cm, plana, estreita a largamente elíptica, base cordada, ápice arredondado a agudo, margem esparsamente serreada e ciliada, face adaxial verde-escura, às vezes com uma faixa branca ou verde-clara ao longo da nervura principal, face abaxial verde-clara a lilás, cinco a sete nervuras principais. Tirsóides $4-8,2 \mathrm{~cm}$ compr. Flores 17,5-22 mm compr. Hipanto 5-5,4× ca. $5 \mathrm{~mm}$, curto-cilíndrico. Sépalas e dentes externos fusionados ca. $4 \mathrm{~mm}$ compr., triangulares, margem curto-fimbriada, ambas superfícies revestidas por glândulas curto-pedunculadas e tricomas simples. Pétalas brancas a rósea-claro, 8-13,5 × 7,5-12 $\mathrm{mm}$, irregularmente obovadas, base levemente atenuada, ápice agudo e apiculado, apículo ca. 0,5 $\mathrm{mm}$ compr., sem tricoma no ápice, margem inteira, ambas superfícies papilosas, glabras. Estames 8-10 $\mathrm{mm}$ compr.; filetes 4,5-5,5 $\mathrm{mm}$ compr.; anteras amarelas, 3,5-4,5 mm compr., oblongo-subuladas, onduladas, poro introrso; pedoconectivo ca. $0,5 \mathrm{~mm}$ abaixo das tecas, dorsalmente calcarado. Estilete 7-8 mm compr., reto, com tricomas simples na base. Cápsula 7-9 × 6,2-9 mm; sementes 0,5-0,7 mm compr.

Material examinado: Domingos Martins, 17.VI.1947, fl., P.L. Krieger 1266 (RB); Vargem Alta [Cachoeiro de Itapemirim], 3.IX.1948, fr., A.C. Brade 19418 (RB); 10.V.1949, fr., A.C. Brade 19771 (RB); 21.XII.1949, fr., M. Moreira (RB 235760); 16.I.1986, fl., J.F.A. Baumgratz 348, 349, 350, 351 (RB); 17.I.2000, fl., C.M. Sakuragui 890 (UPCB); 7.XII.2008, fl., G.R. Souza 148 (UPCB); 3.I.2009, G.R. Souza fl., 165 (UPCB); 31.XII.2013, fl., $R$. Goldenberg 1702 (UPCB); 21.I.2016, fl. e fr., L.F. Bacci 328 (NY, UEC, UPCB); 21.I.2016, fl. e fr., L.F. Bacci et al. 330 (NY, UEC, UPCB).

Bertolonia formosa é endêmica no estado do Espírito Santo (BFG 2015). A espécie caracteriza-se pelos pecíolos hirsutos no ápice, folhas recobertas por glândulas curto-pedunculadas e tricomas simples esparsos e pelas flores com sépalas com margens curto-fimbriadas. A espécie possivelmente encontra-se ameaçada, pois poucos espécimes foram coletados, apenas nos municípios de Vargem Alta e Domingos Martins, nenhum deles dentro de áreas de proteção (Fig. 2b). A espécie habita encostas úmidas e sombreadas entre 700-800 m alt. (Baumgratz
1990) e foi coletada com flores em dezembro e janeiro e frutos em maio e junho.

3. Bertolonia foveolata Brade, Arq. Jard. Rio Jan. 14: 226. 1956.

Fig. 1e,f

Ervas $15-20 \mathrm{~cm}$ alt. Ramos, folhas, inflorescências e hipanto revestidos por glândulas curto-pedunculadas (menores que $0,1 \mathrm{~mm}$ compr.) e tricomas simples, longos. Folhas opostas, ocasionalmente sub-opostas; pecíolos 1,5-6 cm compr., com tricomas semelhantes aos dos ramos, vilosos; lâmina $6,4-20 \times 3-10,5 \mathrm{~cm}$, bulada/foveolada, estreita a largamente elíptica, base cordada, ápice agudo a obtuso, margem esparsamente serreada, ciliada, face adaxial verdeescura, às vezes verde-clara ao longo da nervura principal, face abaxial verde-clara a lilás, três a cinco nervuras principais. Tirsóides 7,5-13,2 cm compr. Flores 10-12 mm compr. Hipanto ca. 2,5 × 1,8-2 $\mathrm{mm}$, curto-cilíndrico. Sépalas e dentes externos fusionados 1,4-2 $\mathrm{mm}$ compr., elípticas, margem inteira, ambas superfícies revestidas somente por glândulas curto-pedunculadas. Pétalas brancas a róseo-claras, 5,5-7 × 3-7 mm, irregularmente elípticas a obovadas, base levemente atenuada, ápice agudo, não apiculado, margem inteira, não ciliada, ambas superfícies papilosas, glabras. Estames 6-6,5 mm compr.; filetes 3-3,5 mm compr.; anteras amarelas, 2,5-3 mm compr., oblongo-subuladas, onduladas, poro introrso; pedoconectivo ca. $0,5 \mathrm{~mm}$ abaixo das tecas, dorsalmente calcarado. Estilete ca. $5 \mathrm{~mm}$ compr., curvado no ápice, glabro. Cápsula 5-7 $\times 6-6,5 \mathrm{~mm}$; sementes $0,5-0,7 \mathrm{~mm}$ compr.

Material examinado: Vargem Alta [Cachoeiro de Itapemirim], 2.IX.1948, fr., A.C. Brade 19411 (RB); 5.V.1949, fr., A.C. Brade 19998 (RB); 22.XII.1949, fl., M. Moreira (MBML, RB 541357); 22.XII.1949, fl., M. Moreira (MBML, RB 662440); 22.XII.1949, fl., M. Moreira (MBML, RB 662348); 16.I.1986, fr., J.F. Baumgratz 352, 355 (RB); 21.I.2016, fr., L.F. Bacci 329 (NY, UEC, UPCB).

Bertolonia foveolata é endêmica no Espírito Santo (BFG 2015). A espécie caracteriza-se pelas folhas com superfície bulada/foveolada, pecíolos vilosos e pelas sépalas com margem inteira. Assim como B. formosa, nenhuma de suas poucas populações ocorre dentro de alguma área de proteção e possivelmente encontra-se ameaçada. Seus espécimes ocorrem simpatricamente com os de B. formosa, no município de Vargem Alta (Fig. 2c). Eles habitam encostas úmidas e sombreadas entre 700-800 m alt. (Baumgratz 1990) e foram coletados com flores em dezembro e frutos em janeiro, maio e outubro. 
4. Bertolonia macrocalyx Bacci \& R.Goldenb., PeerJ 4: e2822, p. 8. 2016.

Fig. $1 \mathrm{~g}$

Ervas ca. $20 \mathrm{~cm}$ alt. Ramos, folhas, inflorescências e hipanto revestidos por glândulas curto-pedunculadas (menores que $0,1 \mathrm{~mm}$ compr.). Folhas opostas, ocasionalmente sub-opostas; pecíolos 1,5-5,3 cm compr., também com tricomas simples, longos, concentrados no ápice; lâmina 10-13,5 × 4,7-6,3 cm, plana, estreitamente elíptica a lanceolada, base levemente cordada, ápice arredondado a levemente agudo, margem inteira a levemente crenulada e ciliada, face adaxial verde-escura, com uma faixa verde-clara ao longo da nervura principal, face abaxial verde-clara a lilás, três a cinco nervuras principais. Tirsóides 11,3-16,2 cm compr. Flores 9,5-11,2 mm compr. Hipanto 2,5-2,7 × $2 \mathrm{~mm}$, curto-cilíndrico, além de tricomas simples, longos, esparsos. Sépalas

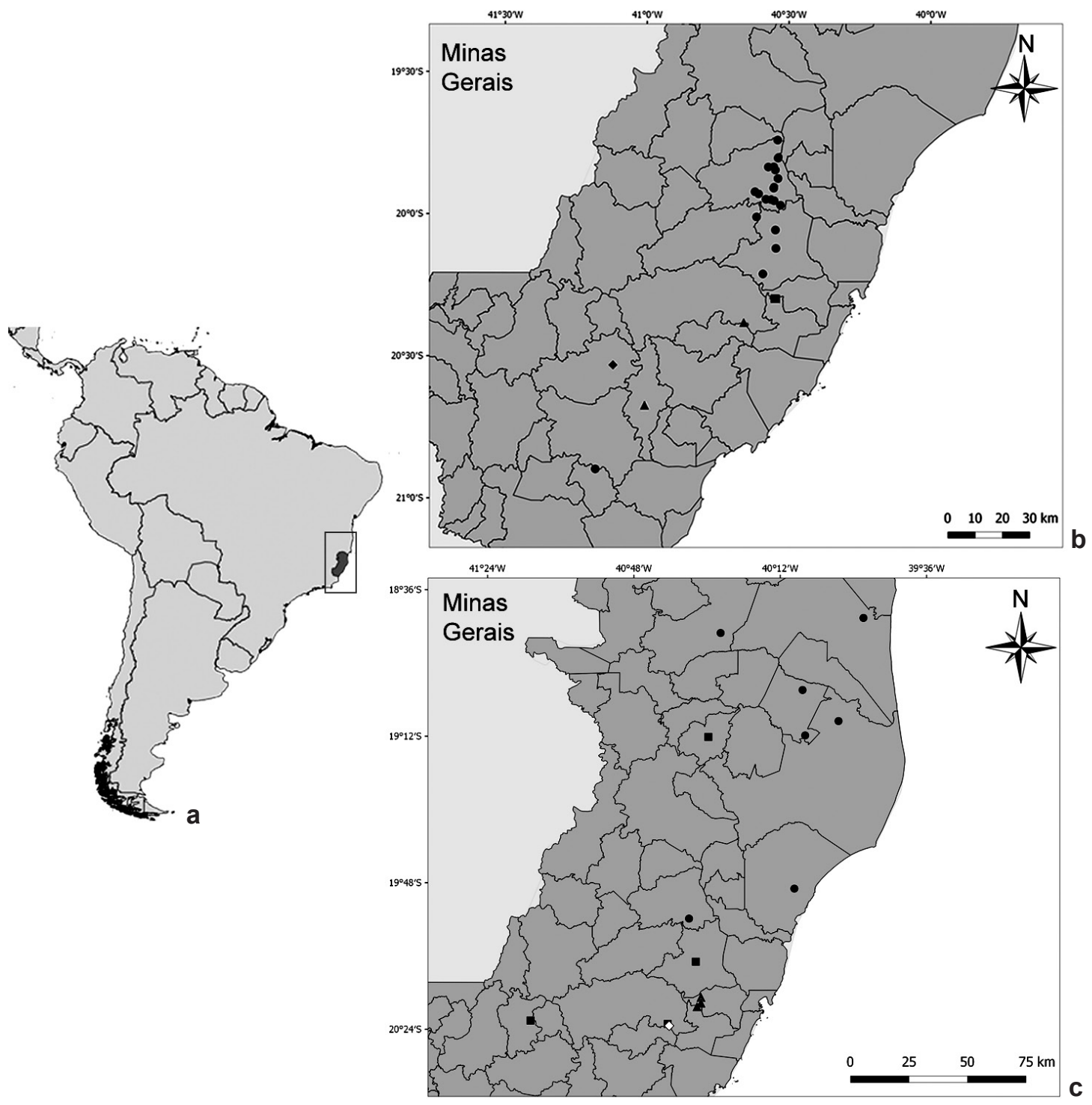

Figura 2 - Mapa com a distribuição das espécies de Bertolonia no Espírito Santo - a. América do Sul, com o Espírito Santo em cinza; b. distribuição de B. formosa $(\boldsymbol{\Delta})$, B. macrocalyx $(\boldsymbol{\square})$, B. mosenii $(\diamond)$ e B. ruschiana $(\bullet)$; c. distribuição de B. duasbocaensis $(\boldsymbol{\Delta})$, B. foveolata $(\diamond)$, B. maculata $(\bullet)$ e B. wurdackiana $(\boldsymbol{\square})$.

Figure 2 - Map with the distribution of Bertolonia in the state of Espírito Santo - a. South America, the state of Espírito Santo in grey;

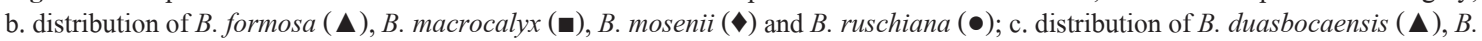
foveolata $(\diamond)$, B. maculata $(\bullet)$ e B. wurdackiana $(\boldsymbol{\square})$. 
truncadas, dentes externos ca. 2 mm compr., ovados, ambos revestidos somente por glândulas curto-pedunculadas. Pétalas brancas com o ápice rósea-claro, 7-8,5 × 3-3,5 $\mathrm{mm}$, irregularmente elípticas, base levemente atenuada, ápice agudo e apiculado (ca. 0,5 mm compr.), apículo com um tricoma simples no ápice, margem inteira, ambas superfícies papilosas, ápice da face adaxial com glândulas curto-pedunculadas esparsas. Estames 6-6,5 mm compr.; filetes 3,5-4 mm compr.; anteras amarelas, 2-2,5 mm compr., oblongosubuladas, levemente onduladas, poro introrso; pedoconectivo ca. $1,5 \mathrm{~mm}$ abaixo das tecas, dorsalmente calcarado. Estilete ca. $5 \mathrm{~mm}$ compr., curvado no ápice, glabro. Cápsulas 3,5-5 × 4,5-5,3 $\mathrm{mm}$; sementes não vistas.

Material examinado: Cariacica, 6.V.2008, fr., C.N. Fraga 2049 (MBML, RB, UPCB). Viana, 17.I.2009, fl., R. Goldenberg 1235 (MBML, RB, UPCB).

Bertolonia macrocalyx é endêmica no estado do Espírito Santo (Bacci et al. 2016a). A espécie caracteriza-se pelas folhas recobertas por glândulas curto-pedunculadas, flores com sépalas truncadas e dentes externos ovados e ciliados e pelas pétalas curto-apiculadas com o ápice recoberto por glândulas curto-pedunculadas na face adaxial. Bertolonia macrocalyx foi coletada somente duas vezes em municípios vizinhos [Cariacica e Viana (Fig. 2b)], fora dos limites da Reserva Biológica de Duas Bocas, na encosta de estrada ou dentro de propriedades privadas. Seus espécimes habitam encostas úmidas e sombreadas entre 500-600 m alt. (Bacci et al. 2016a). Coletada com flores em janeiro e com frutos em janeiro, maio e junho. De acordo com os parâmetros da IUCN (IUCN Standards and Petitions Subcommittee 2014), B. duasbocaensis foi classificada por Bacci et al. (2016a) como "criticamente ameaçada" (CR).

5. Bertolonia maculata DC., Prodr. 3: 114. 1828. Ervas 5-20 cm alt. Ramos, folhas, inflorescência e hipanto revestidos por glândulas curto-pedunculadas (menores que $0,1 \mathrm{~mm}$ compr.) e também tricomas simples, longos. Folhas opostas, ocasionalmente sub-opostas; pecíolos 0,5-6 cm compr., com tricomas semelhantes aos dos ramos, glanduloso-piloso ou glanduloso-viloso em toda sua extensão; lâmina 4-15 × 2,2-10 cm, plana, largamente elíptica a ovada, base cordada, ápice arredondado a obtuso, margem levemente crenulada, ciliada, face adaxial verde-escura, às vezes com uma faixa vinácea ao longo da nervura principal, face abaxial verde-clara, três a cinco nervuras principais. Tirsóides $5-10 \mathrm{~cm}$ compr. Flores ca. $12 \mathrm{~mm}$ compr. Hipanto 2,5-4 × 3,2-4 $\mathrm{mm}$, cilíndrico, revestido por tricomas semelhantes aos das folhas, além de tricomas simples, longos. Sépalas e dentes externos fusionados 1,5-2,5 mm compr., ovados, margem inteira, revestidos por indumento semelhante ao do hipanto. Pétalas rosas, 7,5-9 × 3,5-4 mm, obovadas, base levemente atenuada, ápice agudo e apiculado, apículo ca. 0,7 mm compr., sem tricoma no ápice, margem inteira, ciliada no ápice, glabras. Estames 6-8 mm compr.; filetes 3-4 mm compr.; anteras amarelas, 3-4 mm compr., oblongo-lineares, levemente onduladas, poro introrso; pedoconectivo ca. $1 \mathrm{~mm}$ abaixo das tecas, inapendiculado. Ovário glabro; estilete ca. $7 \mathrm{~mm}$ compr., reto, glabro. Cápsula 4,5-7 × 7-10 mm; sementes $0,5-0,8 \mathrm{~mm}$ compr.

Material examinado: Aracruz, 4.XI.2009, fr., D.A. Folli 6456 (CVRD). Domingos Martins, 7.V.1985, fr., G. Martinelli 10864 (RB). Linhares, 14.XII.1981, fl., H.C. Lima 1656 (SPF, RB); 12.V.1985, fl., G. Martinelli 10967 (RB); 23.III.1986, fl., M. Sobral 4721 (CVRD, RB); 15.X.1992, fl., G.G. Hatschbach 58152 (NY, MBM, UPCB); 10.XI.1994, fr., D.A. Folli 2416 (CVRD); 7.X.2002, fr., D.A. Folli 4366 (CVRD); 25.V.2007, fr., G.S. Siqueira 314 (CVRD); 19.IV.2011, fr., D.F. Lima 257 (ESA, UPCB); 17.V.2014, fr., C. Snak \& C. Silva 1167 (CVRD). Nova Venécia, 15.XI.1953, fr., A.P. Duarte 3708 (RB); fr., 15.XI.1953, A.P. Duarte 3692 (RB); 15.XI.1953, fr., A.P. Duarte 3923 (RB); 15.IV.2009, fl. e fr., C.N. Fraga 2525 (MBML, UPCB). Santa Teresa, 7.XI.1986, fl., G. Martinelli 11893 (RB). São Mateus, 15.V.1977, fl. e fr., G. Martinelli 2210 (RB). Sooretama, 22.VII.1969, fl. e fr., D. Sucre 5739 (RB); 26.IIX.2012, fr., T.B. Flores \& G.O. Romão 1176 (RB, UPCB); 24.IIX.2007, fl., R. Tsuji 2056 (CVRD).

Bertolonia maculata ocorre nos estados do Espírito Santo e Bahia (Baumgratz 1990; BFG 2015). A espécie caracteriza-se pelos pecíolos glanduloso-pilosos ou glanduloso-vilosos, pelas folhas largamente elíptica a ovada com a base cordada, revestidas por glândulas curtopedunculadas e tricomas simples, pelas flores com pétalas rosadas com margens ciliadas no ápice e estames com pedoconectivo inapendiculado. Bertolonia maculata é a espécie mais coletada e amplamente distribuída no estado, tendo sido coletada em sete municípios. Algumas de suas populações são encontradas dentro da Reserva Florestal Vale do Rio Doce (Fig. 2c). Espécimes foram encontrados em encostas úmidas e sombreadas, a sua maioria em Florestas de Tabuleiro. Coletada com flores em abril, maio, julho, agosto, outubro e dezembro e com frutos em abril, maio, agosto, outubro e novembro. 
6. Bertolonia michelangeliana Bacci \& R.Goldenb. sp. nov.

Figs. 3; 5

Tipo: BRASIL. ESPÍRITO SANTO: Santa Leopoldina, Pedra Branca, Mata na Serra Santa Lúcia, prop. Cristiano Bremencampi, 20¹'36”S, 40²9'32”O, alt. 300-600 m, 30 novembro 2007, fl. e fr., V. Demuner, T.A. Cruz \& M. Belisário 4654 (Holótipo: MBML!)

Diagnose: Bertolonia michelangeliana is similar to B. alternifolia Baumgratz, Amorim \& A.B. Jardim. Both share alternate leaves and anthers dehiscent through an extrorse pore. However, the new species is sparsely covered with unbranched trichomes, caducous on branches (vs. densely covered with persistent unbranched trichomes throughout in B. alternifolia), usually longer petioles, $3.2-13.6 \mathrm{~cm}$ long ( $v s$. shorter petioles, $1.8-5.5 \mathrm{~cm}$ long), leaves with 7-9 main veins ( $v s$. leaves with 3-5 main veins), shorter flowers, $12-14 \mathrm{~mm}$ long (vs. longer flowers, 19.5-22.5 mm long), pedicels covered only with short-stalked glands ( $v s$. pedicels also covered with unbranched trichomes) and smaller petals, 10-13 × 6-7.2 mm, white to light pink ( $v s$. bigger petals, $16-18 \times 8.5-10 \mathrm{~mm}$, pink).

Descrição: Ervas 10-20 cm alt., terrestres, rupícolas, reptantes; raízes adventícias ramificadas, crescendo ao longo do caule, maiores em sua porção basal; ramos 4-6 mm larg., arredondados e levemente costados, plagiotrópicos, ramos velhos plagiotrópicos, áfilos, jovens sustentando as folhas, eretos. Ramos jovens, pecíolos e inflorescência revestidos por glândulas curto-pedunculadas (menores que $0,1 \mathrm{~mm}$ compr.) e tricomas simples longos (ca. $2 \mathrm{~mm}$ compr.). Folhas alternas; pecíolos 3,2-13,6 cm compr., cilíndricos, revestidos por tricomas semelhantes aos dos ramos, hirsutos; lâmina $5,5-11,7 \times 4,2-8 \mathrm{~cm}$, plana, largamente ovada a elíptica, raro cordiforme, cartácea, base cordada a cordado-lobada, ápice arredondado a retuso, margem inteira, raro levemente denteada, ciliada, face adaxial verde-escura, abaxial verde-clara a vinácea, ambas revestidas por glândulas curto-pedunculadas e tricomas simples, longos, mais densos na face adaxial, sete a nove nervuras, mais um par marginal que não alcança o ápice da folha, basais, nervuras principais na face abaxial com domácias em suas bases. Tirsóides 5,5-12 cm compr. (16,3-20 cm compr. em infrutescências velhas), terminais (mas pseudoterminais nos espécimes com frutos velhos), com um par de paracládios, estes cimosos, escorpioides, ramos esverdeados a amarronzados; bractéolas 0,5-0,6 mm compr., estreitamente triangulares, ápice acuminado, ambas superfícies revestidas por glândulas curto-pedunculadas. Flores 5-meras, 12-14 $\mathrm{mm}$ compr., pedicelos ca. $1 \mathrm{~mm}$ compr., revestidos por glândulas curto-pedunculadas. Hipanto verdeclaro, $2-2,5 \times$ ca. $2 \mathrm{~mm}$, arredondado, 10-costado, com tricomas semelhantes aos do pedicelo e tricomas simples, longos. Cálice caduco nos frutos, tubo ca. $0,8 \mathrm{~mm}$ compr., sépalas e dentes externos fusionados 3-4 mm compr., longo-triangulares a elípticos, margem inteira, ciliada no ápice, verde-claras, revestida por indumento semelhante ao do hipanto. Pétalas brancas a róseo-claras, 10-13 × 6-7,2 $\mathrm{mm}$, elípticas a obovadas, base arredondada, ápice agudo e apiculado, apículo ca. 0,5 $\mathrm{mm}$ compr., sem tricoma no ápice, margem inteira, ambas superfícies papilosas, glabras. Estames 10,9-11,5 mm compr., isomórficos; filetes 6-7 mm compr., papilosos, levemente engrossados na base; anteras amarelas, 4-5,3 mm compr., longo-subuladas, levemente onduladas, com o ápice alongado, poro extrorso; pedoconectivo ca. $1 \mathrm{~mm}$ compr., inapendiculado, raro giboso dorsalmente. Ovário livre, ápice glabro, 3-locular, placentação axilar; estilete ca. $12 \mathrm{~mm}$ compr., reto, glabro; estigma levemente capitado, papiloso. Cápsula tipo bertolonídio, 5-7 × 6,2-7,5 $\mathrm{mm}$; sementes ca. $0,6 \mathrm{~mm}$ compr., triangulares, tuberculadas nos ângulos dorsais.

Distribuição e status de conservação: Bertolonia michelangeliana foi coletada somente no estado do Espírito Santo. Os espécimes estão distribuídos em quatro municípios [Cariacica, Marilândia, Santa Leopoldina e Santa Teresa (Fig. 4)], todos localizados na região central do estado. Somente uma população foi encontrada dentro de uma área de proteção. A Reserva Biológica de Duas Bocas é uma área de proteção permanente mantida pelo governo do estado (IEMA/ES), cuja área abriga fragmentos bem preservados de Floresta Ombrófila Densa Submontana e protege espécies ameaçadas da fauna e flora brasileiras (Novelli 2010). No último ano, duas novas e ameaçadas espécies de Bertolonia foram descritas para Duas Bocas, B. duasbocaensis e B. macrocalyx (Bacci et al. 2016a). Espécimes de $B$. michelangeliana são predominantemente rupícolas em pequenos afloramentos rochosos dentro da mata, às vezes rastejantes ou hemiepífitos em ambientes úmidos e sombreados. Coletada com flores em janeiro e novembro e frutos em janeiro, fevereiro a maio e novembro. De acordo com a IUCN Standards and Petitions Subcommittee (2014) critérios B1ab(ii) + B2ab(ii), com EOO (Extensão de Ocorrência) = $635,735 \mathrm{~km}^{2}$ e AOO (Área de Ocupação) $=36,000$ $\mathrm{km}^{2}$, B. michelangeliana deve ser classificada como "em perigo" (EN). 

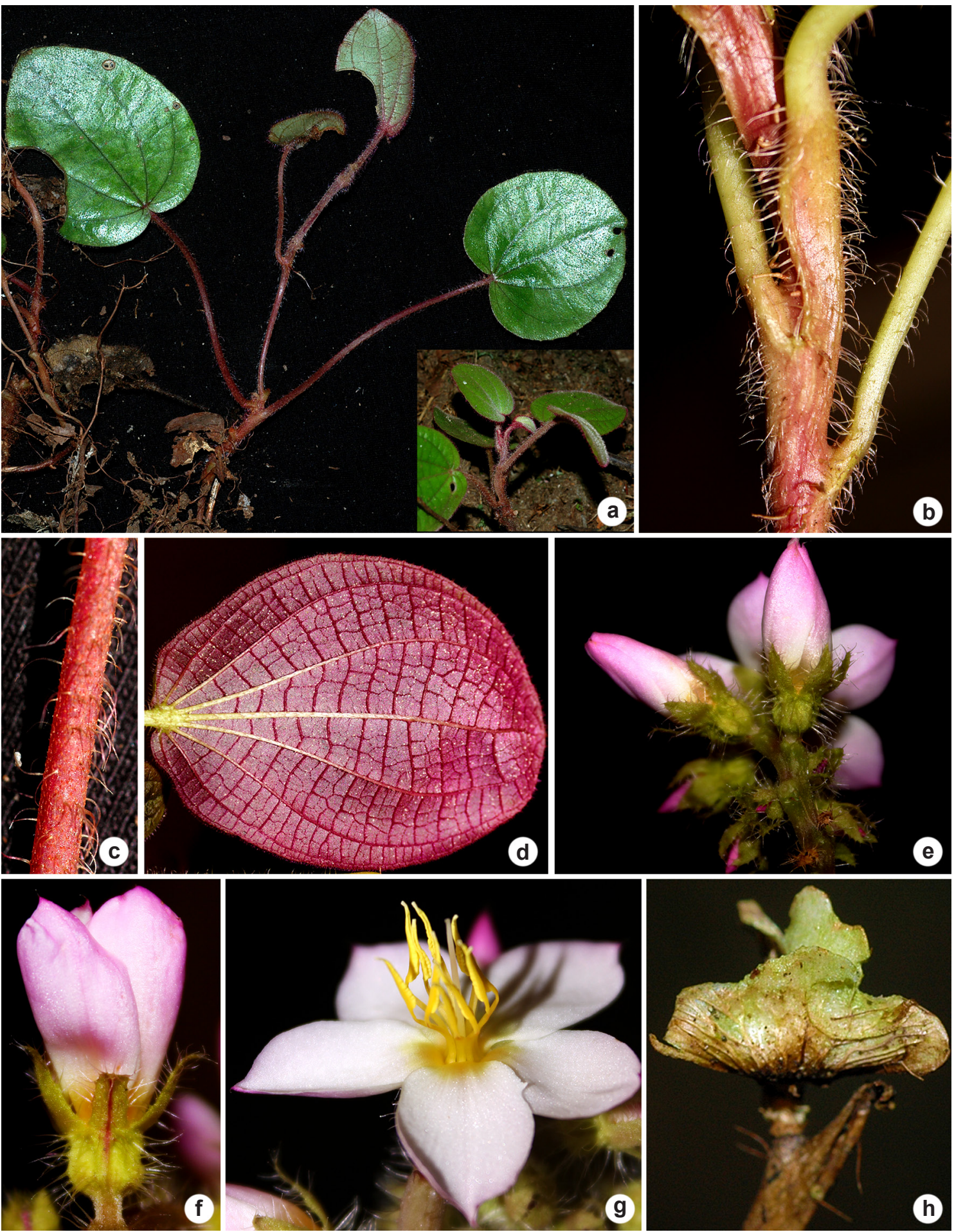

Figura 3 - Bertolonia michelangeliana - a. hábito; b. ramo e pecíolos; c. pecíolo evidenciando as glândulas curtopedunculadas e tricomas simples; d. lâmina foliar, face abaxial; e. inflorescência com botões florais; f. botão floral; $g$. flor; h. fruto velho. [a,h. R. Goldenberg \& F. Michelangeli 898 (MBML); b-g. L.F. Bacci et al. 381 (NY)].

Figure 3-Bertolonia michelangeliana - a. habit; b. branch and petioles; c. petiole covered with sessile and short-stalked glands and unbranched trichomes; d. abaxial surface of the leaf blade; e. inflorescence with flower buds; f. flower bud; g. flower; h. old fruit. [a,h. R. Goldenberg \& F. Michelangeli 898 (UPCB); b-g. L.F. Bacci et al. 381 (NY)]. 
Material examinado: Cariacica, 10.IV.2009, fr., J. Meirelles 303 (RB). Marilândia, 25.V.2006, fr., $V$. Demuner 2341 (MBML); 14.VI.2007, fl. e fr., $V$. Demuner 4273 (MBML). Santa Leopoldina, 19.II.2006, fr., $V$. Demuner 1851 (MBML); 30.III.2006, fl. e fr., $V$. Demuner 2148 (MBML); 19.I.2007, fr., R. C. Britto 157 (MBML); 16.V.2006, fr., L.F.S. Magnago 973 (MBML); fr., 13.III.2007, V. Demuner 3141 (MBML); 17.IV.2007, fr., $V$. Demuner 3569 (MBML); 29.I.2008, fl. e fr., $V$. Demuner 4913 (MBML); 16.IV.2013, fr., R.C. Forzza 7498 (RB); 11.IV.2009, fr., R. Goldenberg 1442 (CEPEC, MBML, RB). Santa Teresa, 23.II.2007, fr., A.P. Fontana 2981 (MBML, RB); fr., R. Goldenberg 898 (UPCB). Localidade desconhecida, cultivada na estufa do Jardim Botânico de Nova Iorque, fl. e fr., 14.VII.2016, L.F. Bacci 381 (NY).

Etimologia: O epíteto "michelangeliana" homenageia Dr. Fabián A. Michelangeli do Jardim Botânico de Nova Iorque. Além de um dos principais especialistas em filogenia e taxonomia de Melastomataceae, o homenageado nos indicou os indivíduos cultivados na estufa do Jardim Botânico de Nova Iorque.

Discussão: Bertolonia michelangeliana caracteriza-se pelas folhas alternas revestidas por glândulas curto-pedunculadas, e tricomas simples, longos, mais densos na face adaxial da lâmina, pelas pétalas brancas a rosadas e anteras longosubuladas, deiscentes por um poro extrorso. A espécie assemelha-se a $B$. alternifolia, que também possui folhas alternas e é endêmica da Bahia. No entanto, B. michelangeliana distingue-se por ser esparsamente recoberta por tricomas simples, caducos nos ramos (vs. planta densamente recoberta por tricomas simples em $B$. alternifolia), pecíolos mais longos, 3,2-13,6 cm compr. (vs. pecíolos mais curtos, 1,8-5,5 cm compr.), lâmina foliar com 7-9 nervuras principais (vs. lâmina foliar 3-5 nervuras principais), flores menores, $12-14 \mathrm{~mm}$ compr. (vs. flores maiores, 19,5-22,5 mm compr.), pedicelos recobertos somente por glandulas curtopedunculadas ( $v s$. pedicelos recobertos também por tricomas simples) e pelas pétalas menores, 10-13 × 6-7,2 mm, brancas a rosadas (vs. pétalas maiores, $16-18 \times 8,5-10 \mathrm{~mm}$, róseas). Bertolonia michelangeliana parece ser morfologicamente próxima a $B$. maculata $\mathrm{DC}$., distribuída nos estados da Bahia e Espírito Santo (BFG 2015) e a $B$. marmorata (Naudin) Naudin, com ocorrência nos

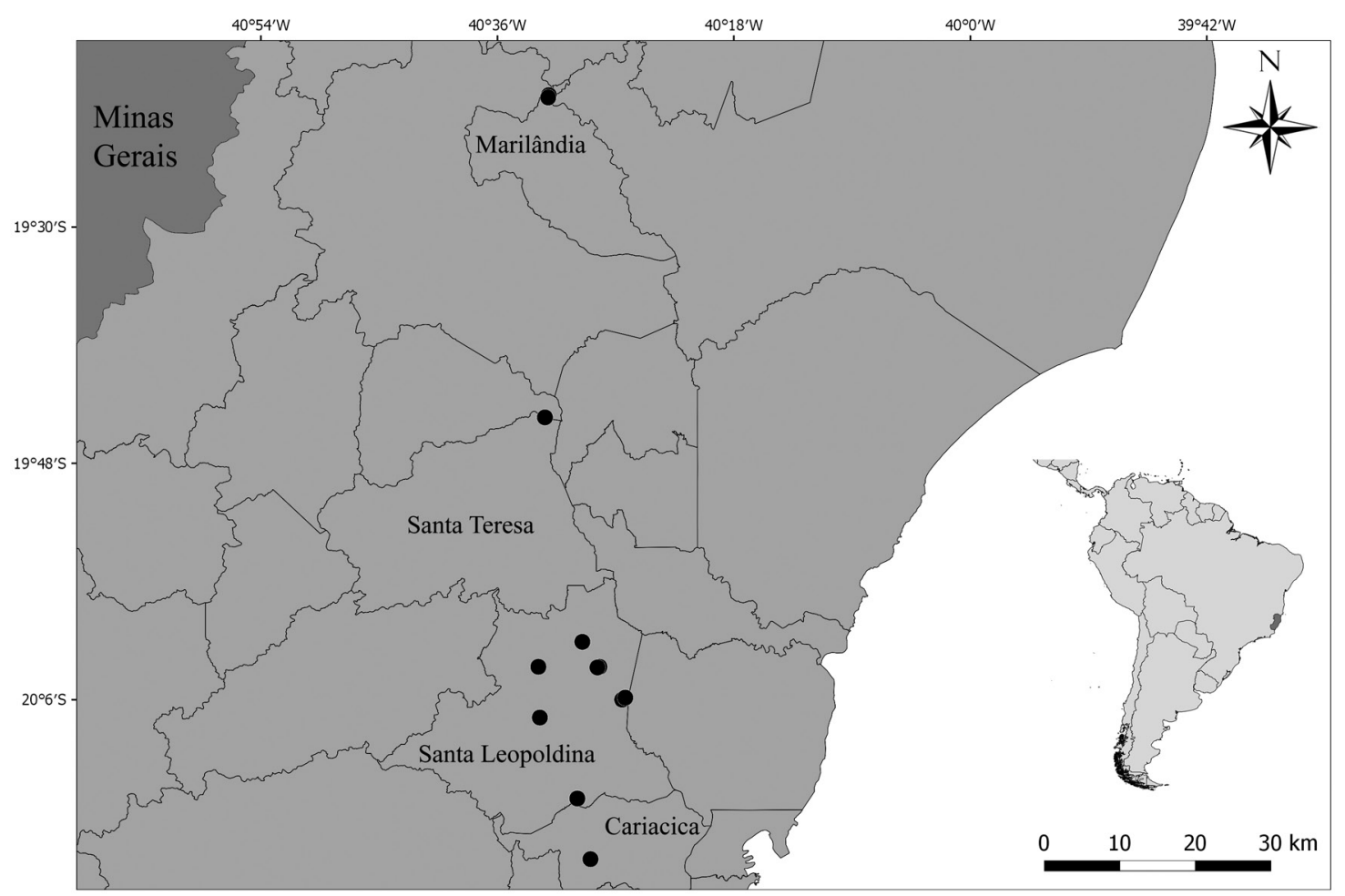

Figura 4 - Mapa com os pontos de coleta de Bertolonia michelangeliana.

Figure 4 - Map with the collection points of Bertolonia michelangeliana. 


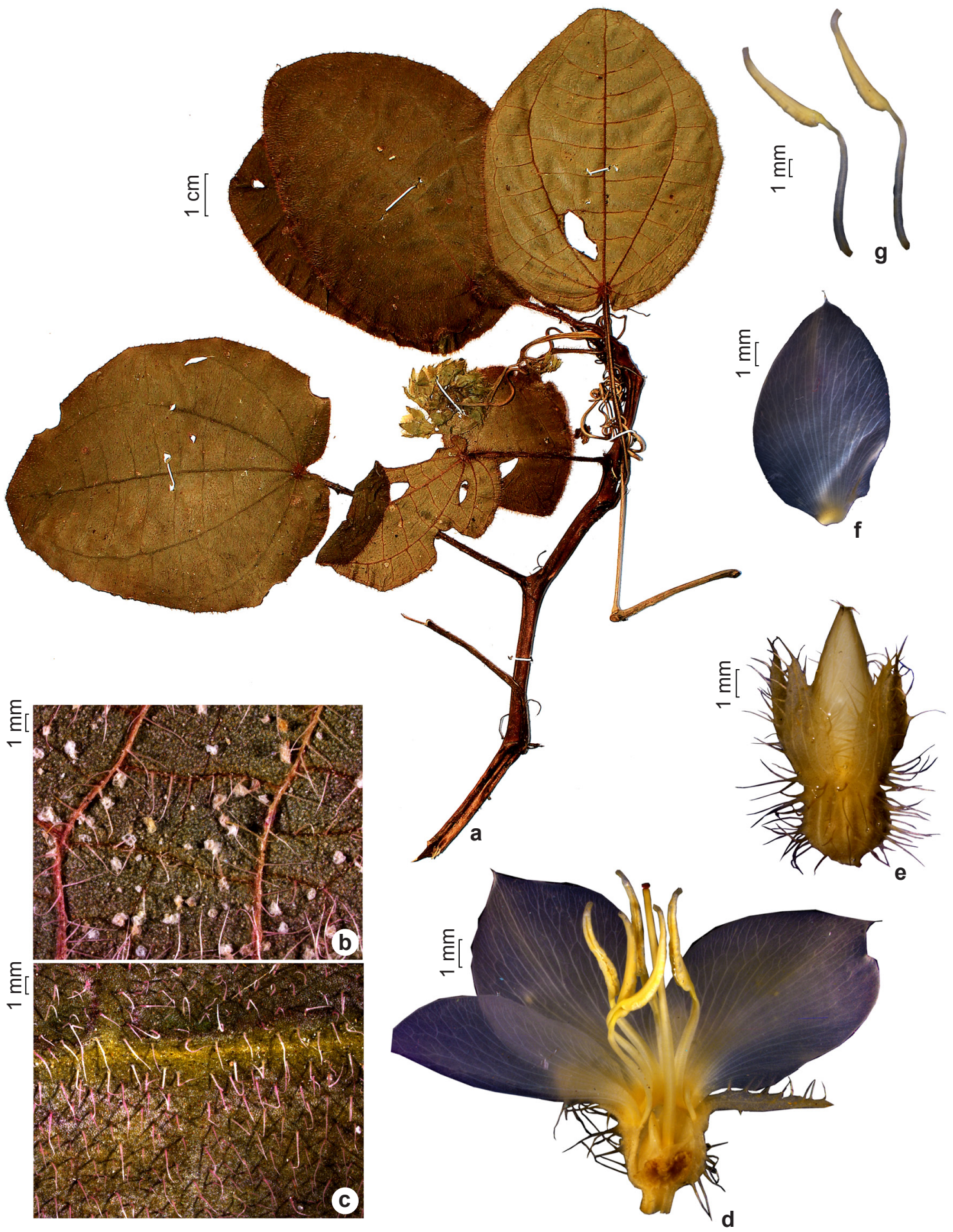

Figura 5 - Bertolonia michelangeliana - a. hábito; b. lâmina foliar, face abaxial; c. lâmina foliar, face adaxial; d. flor, secção longitudinal; e. botão floral; f. pétala; g. estames. [a. V. Demuner 4654 (MBML); b-g. L.F. Bacci 381 (NY)]. Figure 5 - Bertolonia michelangeliana - a. habit; b. abaxial surface of the leaf blade; c. adaxial surface of the leaf blade; d. longitudinal section of the flower; e. flower bud; f. petal; g. stamens. [a. V. Demuner 4654 (MBML); b-g. L.F. Bacci 381 (NY)]. 
estados da Bahia, Pernambuco e Alagoas (BFG 2015), com base no tipo de indumento e forma dos estames. Bertolonia michelangeliana difere dessas duas espécies principalmente pelas folhas alternas (vs. opostas em B. maculata e B. marmorata), pétalas brancas a rosa-claras e estames amarelos (vs. pétalas rosas e estames creme) e anteras deiscentes através de um poro extrorso ( $v s$. anteras deiscentes através de um poro introrso).

7. Bertolonia mosenii Cogn. in Mart., Fl. bras. 14(4): 55.1886.

Fig. 1h,i

Ervas ca. $15 \mathrm{~cm}$ alt. Ramos e pecíolos revestidos por glândulas curto-pedunculadas (menores que $0,1 \mathrm{~mm}$ compr.) e também por tricomas simples, longos, caducos. Folhas opostas, ocasionalmente sub-opostas; pecíolos 2,8-5,5 cm compr., com tricomas semelhantes aos dos ramos; lâmina 5-8,5 × 4-6,5 cm, plana, ovada a largamente elíptica, base aguda a obtusa, ápice agudo, margem serreada e ciliada, face adaxial verde-escura, face abaxial verde-clara, ambas revestidas por glândulas curto-pedunculadas, três nervuras principais. Tirsóides 6-7 cm compr. Flores não vistas. Cápsula 5-7 × ca. $6 \mathrm{~mm}$; sementes não vistas.

Material examinado: Castelo, 15.X.2008, fr., C.N. Fraga 2249 (MBML, RB, UPCB); 19.V.2010, fr., J. Meirelles 449 (RB).

Apesar de Bertolonia mosenii ser a espécie com a maior distribuição dentro do gênero, ocorrendo em Santa Catarina, Paraná, São Paulo, Minas Gerais e Rio de Janeiro (Baumgratz 1990; BFG 2015), é pouco coletada no estado do Espírito Santo. Os dois espécimes examinados foram coletados no município de Castelo, dentro do Parque Estadual do Forno Grande (Fig. 2b). Ao contrário de sua distribuição no sul do país, $B$. mosenii é raramente encontrada no Espírito Santo e sua preservação no estado depende da manutenção do Parque. Apesar de não ter sido coletada com flores, os espécimes tem caracteres vegetativos que possibilitam a identificação da espécie, como as folhas pequenas ovadas a largamente elípticas com base aguda ou obtusa. Coletada em Floresta Ombrófila Densa Altomontana entre 1200-1300 $m$ alt., com frutos em maio e outubro.

8. Bertolonia ruschiana Bacci \& R.Goldenb., PeerJ 4: e2822, p. 12. 2016.

Fig. $1 \mathrm{j}, \mathrm{k}$

Ervas 10-40 $\mathrm{cm}$ alt. Ramos, folhas, inflorescência e hipanto revestidos por glândulas curto-pedunculadas (menores que $0,1 \mathrm{~mm}$ compr.). Folhas opostas, ocasionalmente sub-opostas; pecíolos 1,5-6,4 cm compr., com tricomas semelhantes aos dos ramos, também com tricomas simples, longos, concentrados no ápice; lâmina 9-18,5 × 4,5-10,5 cm, plana, ovada a largamente elíptica, base levemente cordada, ápice arredondado a levemente agudo, às vezes mucronulado, margem crenulada, ciliada, face adaxial verde-escura ou com uma faixa verde-clara ou branca ao longo da nervura principal, face abaxial verde-clara a lilás, cinco nervuras principais. Tirsóides $3,2-9,5 \mathrm{~cm}$ compr. Flores 8-9 mm compr. Hipanto $2-2,5 \times \mathrm{ca}$. $2 \mathrm{~mm}$, largamente campanulado. Sépalas ca. 1,5 $\mathrm{mm}$ compr., largamente ovadas, margem inteira, com tricomas semelhantes aos do hipanto, às vezes com um tricoma simples na ponta das costas entre as sépalas, dentes externos $0,5-0,7 \mathrm{~mm}$ compr., triangular, levemente côncavo. Pétalas brancas com o ápice rósea-claro, 6-6,5 × 5,7-6 mm, largamente obovadas, base levemente atenuada, ápice agudo a obcordado, não apiculado, margem inteira, ambas superfícies papilosas, ápice da face adaxial com glândulas curto-pedunculadas esparsas. Estames 6-7,5 mm compr.; filetes $3,5-4,5 \mathrm{~mm}$ compr.; anteras amarelas, 2,5-3 $\mathrm{mm}$ compr., oblongosubuladas, levemente onduladas, poro introrso; pedoconectivo 0,7-0,9 $\mathrm{mm}$ compr., dorsalmente calcarado. Estilete ca. $6 \mathrm{~mm}$ compr., curvado no ápice, glabro. Cápsula 5,5-7×6-7,5 mm; sementes 0,5-0,7 mm compr.

Material examinado: Atílio Vivacqua, 26.I.1994, fr., E. Bausen 60 (MBML, SPF, UPCB). Santa Leopoldina, 24.X.1988, fr., V. Krause (MBML 5295); 31.X.2006, fr., L.F.S. Magnago 1523 (MBML); 16.III.2007, fr., A.P. Fontana 3050 (MBML, RB, UPCB). Santa Maria de Jetibá, 6.V.2001, fr., L.C. Kollmann 3650 (MBML). Santa Teresa, 11.IV.1985, fr., W. Boone 333 (MBML); 1.X.1985, fr., H.Q.B. Fernandes 1527 (MBML); 3.VII.1986, fr., H.Q.B. Fernandes 2003 (MBML); 5.III.1990, fl., L.C. Kollmann 2039 (MBML); 23.XII.1993, fr., E. Bausen 53 (MBML, SPF, UPCB); 7.I.1994, fl. e fr., E. Bausen 54 (MBML, SPF, UPCB); 17.I.1995, fr., C.C. Chamas 375 (MBML); 24.I.1995, fl., C.C. Chamas 380 (MBML); 5.III.1999, fl. e fr., L.C. Kollmann 2039 (MBML); 19.IV.2000, fr., L.C. Kollmann 2869 (MBML); 6.VI.2001, fr., L.C. Kollmann 3816 (MBML); 23.VI.2001, fr., A.P. Fontana 132 (MBML); 6.VI.2001, fr., L.C. Kollmann 3816 (MBML); 14.IX.2001, fr., L.C. Kollmann 4553 (MBML, RB); 5.II.2002, fl. e fr., L.C. Kollmann, L. 5499 (MBML, RB, UPCB); 22.I.2003, fl., R.R. Vervloet 1718 (MBML); 5.II.2003, fl., R.R. Vervloet 1777 (MBML, RB, UPCB); 29.III.2003, fr., A.P. Fontana 545 (MBML, UPCB); 1.IV.2003, fr., R.R. Vervloet 2095 (MBML); 20.I.2005, fl., H.Q.B. Fernandes 3373 (MBML, UPCB),; 26.I.2005, fl., L.C. Kollmann 7308 (MBML); 26.I.2005, fl., L.C. Kollmann 7328 (MBML); 22.V.2005, fr., R.C. 
Britto 58 (MBML); 24.II.2006, fr., L.C. Kollmann 8675 (MBML); 23.II.2007, fr., A.P. Fontana 2980 (MBML, RB); 10.VII.2007, fr., R. Goldenberg 891 (UPCB); 13.VII.2007, fr., R. Goldenberg 897 (UPCB); 4.V.2009, fr., A.P. Fontana 5982 (MBML); 7.II.2011, fl. e fr., F.A. Michelangeli 1604 (NY); 7.II.2011, fr., F.A. Michelangeli 1606 (NY); 10.XII.2012, fr., J.A. Lombardi 9819 (UPCB); 27.XI.2013, fr., L.F. Bacci \& D.F. Lima 108 (UPCB); 14.I.2016, fl. e fr., L.F. Bacci 317 (MBML, NY, UEC, UPCB); 14.I.2016, fl. e fr., L.F. Bacci 321 (MBML, NY, UEC, UPCB).

Bertolonia ruschiana é endêmica do Espírito Santo. A espécie caracteriza-se pela face adaxial das folhas, pedicelos e hipanto recobertos somente por glândulas curto-pedunculadas, sépalas ovadas e dentes externos triangulares e levemente côncavos e pelas pétalas com o ápice revestido por glândulas curto-pedunculadas na face adaxial. Bertolonia ruschiana foi coletada várias vezes na região central do estado, em três municípios (Santa Leopoldina, Santa Maria do Jetibá e Santa Teresa; Bacci et al. 2016a), além de uma coleta mais ao sul, no município de Atílio Vivacqua (Fig. 2b). Apesar de coletadas dentro de algumas propriedades particulares, a maioria das populações encontradas estão dentro de três áreas de proteção ambiental, Reserva Biológica Augusto Ruschi, Estação Ecológica de Santa Lúcia e Monumento Natural Municipal de São Lourenço. Coletada com flores de janeiro a março e com frutos o ano todo. De acordo com os parâmetros da IUCN (IUCN Standards and Petitions Subcommittee 2014), B. ruschiana foi classificada por Bacci et al. (2016a) como "em perigo" (EN).

\section{Bertolonia wurdackiana Baumgratz Arq. Jar. Bot. Rio Jan. 30: 134. 1990. \\ Fig. 11}

Ervas 15-35 cm alt. Ramos, folhas e inflorescência revestidos por glândulas curtopedunculadas (menores que $0,1 \mathrm{~mm}$ compr.) e tricomas simples, longos. Folhas opostas, ocasionalmente sub-opostas; pecíolos 0,5-6,2 cm compr., com indumento semelhante ao dos ramos, hirsutos; lâmina 6,5-15 × 3,5-9 cm, bulada/ foveolada, estreitamente ovada a largamente elíptica, base cordada, ápice arredondado a obtuso, margem levemente serreada, ciliada, face adaxial verde-escura ou com uma faixa branca ao longo da nervura principal, face abaxial verde-clara a lilás, três a cinco nervuras principais. Tirsóides 4-5 cm compr. Flores 10-13 mm compr. Hipanto 2,7-3 × ca. $2 \mathrm{~mm}$, curto-cilíndrico. Sépalas e dentes externos fusionados 2,5-3 mm compr., elípticas a estreitamente ovadas, margem fimbriada, com tricomas semelhantes aos do hipanto. Pétalas brancas a rósea-claro, 7,5-8,5 × ca. $4 \mathrm{~mm}$, elíptica a obovada, base levemente atenuada, ápice agudo e apiculado, apículo ca. 0,5 mm compr., sem tricoma no ápice, margem inteira, ambas superfícies papilosas. Estames 5,5-6,5 mm compr.; filetes 3,5$4 \mathrm{~mm}$ compr.; anteras amarelas, 2-2,5 mm compr., oblongo-subuladas, onduladas, poro introrso; pedoconectivo ca. $0,5 \mathrm{~mm}$ compr., dorsalmente calcarado. Estilete ca. 5,5 mm compr., curvado no ápice, glabro. Cápsula 5-8 × ca. $7 \mathrm{~mm}$; sementes 0,5-0,7 mm compr.

Material examinado: Conceição de Castelo, 4.V.1982, fl., G. Martinelli 7999 (RB); 7.V.1985, fr., G. Martinelli $10864 a$ (RB). Domingos Martins, fl., 17.VI.1947, L. Krieger 1266 (RB); 15.IX.1975, fr., J.P.P. Carauta 1809 (RB); 19.I.1977, fl., A.L. Peixoto 447 (RB); 2.V.1974, fr., D. Sucre 10735 (RB). Governador Lindenberg, 21.II.2006, fr., L.F.S. Magnago 701 (MBML). Santa Leopoldina, 30.III.2006, fr., V. Demuner 2160 (MBML, UPCB); 26.V.2015, fr., R. Goldenberg \& J. Freitas 2175 (MBML, NY, UPCB).

Bertolonia wurdackiana é endêmica no estado do Espírito Santo (Baumgratz 1990; BFG 2015). A espécie caracteriza-se pelas lâminas foliares com superfície bulada/foveolada, pecíolos hirsutos, sépalas com margem fimbriada e flores com pétalas brancas. A espécie encontra-se possivelmente ameaçada, pois poucos espécimes foram coletados, em somente quatro municípios [Conceição de Castelo, Domingos Martins, Governador Lindenberg e Santa Leopoldina (Fig. 2c)] e nenhum deles dentro de área de proteção. A espécie habita encostas úmidas e sombreadas entre 500-800 m alt. Coletada com flores em fevereiro, março, maio, junho e outubro e com frutos em janeiro e junho.

\section{Agradecimentos}

Agradecemos aos curadores e equipe dos herbários CEPEC, CVRD, ESA, HUFU, K, MBM, MBML, NY, RB, SPF, UEC, UPCB, US, VIES. Agradecemos também àqueles que nos ajudaram em campo: Ludovic Kollmann, André Fontana, Paulo Labiak, Rafaela Forzza, Julia Meirelles, Thuane Bochorny, Duane F. Lima, Mônica Bolson, e a Fabian Michelangeli, que nos indicou a planta cultivada no NYBG. L.F.B. recebeu bolsa de Doutorado CAPES e CNPq, e R.G. e A.A. receberam bolsa de Produtividade CNPq (306852/2013-6 e 310717/2015-9, respectivamente); o trabalho de laboratório foi financiado parcialmente pelo CNPq (Edital PPBIO Mata Atlântica, 457483/2012-1). 


\section{Referências}

Bacci LF \& Goldenberg R (2015) Miconia valentinensis (Melastomataceae), a new species from Espírito Santo, Brazil. Phytotaxa 195: 272-278.

Bacci LF, Amorim AM \& Goldenberg R (2016a) Three new species of Bertolonia (Melastomataceae) from Espírito Santo, Brazil. PeerJ 4: e2822.

Bacci LF, Amorim AM, Michelangeli FA \& Goldenberg R (2016b) A new species of Bertolonia (Melastomataceae) from southern Bahia, Brazil. Phytotaxa 265: 251-258.

Bacci LF, Caddah MK \& Goldenberg R (2016c) The genus Miconia (Melastomataceae) in Espírito Santo, Brazil. Phytotaxa 271: 1-92.

Baumgratz JFA (1983-1985) Morfologia dos frutos e sementes de Melastomataceas brasileiras. Arquivos do Jardim Botânico do Rio de Janeiro 27: 113-155.

Baumgratz JF (1990) O gênero Bertolonia Raddi (Melastomataceae): revisão taxonômica e considerações anatômicas. Arquivos do Jardim Botânico do Rio de Janeiro 30: 69-213.

Baumgratz JFA, Amorim AM \& Jardim AB (2011) Two new species of Bertolonia (Melastomataceae) from the Brazilian Atlantic Forest. Kew Bulletin 66: 273-279.

BFG - The Brazil Flora Group (2015) Growing knowledge: an overview of seed plant diversity in Brazil. Rodriguésia 66: 1085-1113.

Caddah MK \& Goldenberg R (2012) A new species of Miconia (Melastomataceae) from the Atlantic Forest of Brazil. Systematic Botany 3: 974-977.

Camargo EA \& Goldenberg R (2011) Two new species of Leandra from Espírito Santo, Brazil. Brittonia 63: $220-226$.

Clausing G \& Renner SS (2001) Molecular phylogenetics of Melastomataceae and Memecylaceae: implications for character evolution. American Journal of Botany 88: 486-498.

Dutra VF, Alves-Araújo A \& Carrijo TT (2015) Angiosperm checklist of Espírito Santo: using electronic tools to improve the knowledge of an Atlantic Forest biodiversity hotspot. Rodriguésia 66: 1145-1152.

Garbin ML, Saiter FZ, Carrijo TT \& Peixoto AL (2017) Breve histórico e classificação da vegetação capixaba. Rodriguésia 68: 1883-1894.

Goldenberg R \& Kollmann LJC (2010) A new species of Miconia (Melastomataceae: Miconieae) from Espírito Santo, Brazil. Blummea 55: 139-142.

Goldenberg R \& Kollmann LJC (2016) Two new species of Pleroma (Melastomataceae) from Espírito Santo, Brazil. Brittonia. Brittonia 68: 37-45.
Goldenberg R \& Reginato M (2006) Sinopse da família Melastomataceae na Estação Biológica de Santa Lúcia, Santa Teresa, Espírito Santo. Boletim do Museu Mello Leitão, Nova Série 20: 33-58.

Goldenberg R \& Reginato M (2009) New species of Behuria, Miconia and Ossaea (Melastomataceae) from Eastern Brazil. Journal of the Torrey Botanical Society 163: 293-301.

Goldenberg R \& Tavares RAM (2007) A new species of Dolichoura (Melastomataceae) and broadened circuscription of the genus. Brittonia 56: 989-993.

Iglesias DT, Dutra VF \& Goldenberg R (2016) Behuria mestrealvarensis (Melastomataceae): a new species on an inselberg in Espírito Santo, Brazil. Phytotaxa 25: 281-286.

IUCN - International Union for Conservation of Nature - Standards and Petitions Subcommittee (2014) Guidelines for using the IUCN red list categories and criteria. Version 11 (February 2014). Prepared by the IUCN Species Survival Commission. IUCN Council, Gland, and Cambridge. 87 pp. Disponível em <http://www.iucnredlist.org/documents/ RedListGuidelines.pdf>. Acesso em 27 maio 2017.

Meirelles J \& Goldenberg R (2012) Melastomataceae do Parque Estadual do Forno Grande, Espírito Santo, Brasil. Rodriguésia 63: 831-855.

Meirelles J, Kollmann LJC \& Goldenberg R (2012) Tibouchina tedescoi: a new species in Tibouchina sect. Pleroma (Melastomataceae) from Espírito Santo, Brazil. Kew Bulletin 67: 461-465.

Meyer FS, Goldenberg R \& Kollmann LJC (2016) Three new species of Pleroma (Melastomataceae) from Inselbergs of Espírito Santo, Brazil. Phytotaxa 28: 197-210.

Novelli FZ (2010) A Reserva Biológica de Duas Bocas e seus vínculos com à história da conservação no Espírito Santo. Natureza on Line 8: 57-59.

Mori SA, Silva LAM, Lisboa G \& Coradin L(1989) Manual de Manejo de Herbário Fanerogâmico. 2ª ed. Centro de Pesquisas do Cacau, Ilhéus. 84p.

Pizo MA \& Morellato LP (2002) A new rain-operated seed dispersion mechanism in Bertolonia mosenii (Melastomataceae), a Neotropical rainforest herb. American Journal of Botany 89: 169-171.

Tavares RAM, Baumgratz JFA \& Goldenberg R (2008) Anew species of Behuria Cham. (Melastomataceae: Merianieae) from Brazil. Botanical Journal of the Linnean Society 158: 489-429.

Thiers B [continuamente atualizado]. Index herbariorum: a global directory of public herbaria and associated staff. New York Botanical Garden, New York. Disponível em $<$ http://sciweb.nybg.org/science2/ IndexHerbariorum.asp.>. Acesso em 27 maio 2017. 